\title{
INFLUÊNCIA DAS CARACTERÍSTICAS DO PELLET FEED DE MINÉRIO DE FERRO NA ETAPA DE FILTRAGEM
}

\author{
Karine Fernandes Rodrigues ' \\ Otávia Martins Silva Rodrigues ${ }^{2}$ \\ Rafael de Souza Rodrigues ${ }^{3}$
}

\section{Resumo}

A filtragem é uma operação de separação sólido-líquido fundamental para o processo de pelotização do minério de ferro, atuando no ajuste da umidade do pellet feed. $O$ excesso de umidade prejudica a qualidade das pelotas cruas, com a redução da resistência à compressão. Por outro lado, a umidade muito baixa dificulta a formação da pelota no disco pelotizador. $O$ objetivo do trabalho foi estudar a influência das características intrínsecas do minério na filtragem, relacionando esses parâmetros com informações de umidade da torta e produtividade da operação industrial de filtragem. Foram analisadas amostras de concentrado de duas campanhas distintas de produção, baixa sílica (BS) e alta sílica (AS). $\mathrm{Na}$ campanha BS, o valor de umidade foi igual a $10,2 \%$, enquanto que para a campanha AS foi de $10,4 \%$. O melhor desempenho do minério da campanha BS na filtragem está relacionado ao menor teor de perda ao fogo, menor valor de área superficial específica e menores proporções de minerais porosos ou de maior esfericidade. Em resumo, a mineralogia foi um dos fatores determinantes para justificar as diferenças entre as umidades das tortas.

Palavras-chave: Minério de ferro; Filtragem; Pellet feed; Superfície específica.

\section{INFLUENCE OF IRON ORE PELLET FEED CHARACTERISTCS IN THE FILTERING STAGE}

\begin{abstract}
Filtering is a fundamental process of solid-liquid separation to the production of iron ore pellets, acting in adjusting of the moisture of the pellet feed. Excessive increase in moisture affect the quality of green pellets, with a reduction in compression strength. However low moisture makes it difficult to pellet formation in pelletizing disk. Therefore, it is very important to ensure the ideal moisture in the filtering process. The purpose of this work was to investigate the influence of the intrinsic characteristics of ore in the filtering process, relating these parameters with information about the cake moisture and productivity in the filtering process. One analyzed samples from two different production campaigns, high silica (AS) and low silica (BS). The moisture required of the cake was $10 \%$. In the BS campaign the moisture was $10.2 \%$, while in the AS campaigns the moisture was $10.4 \%$. The main factors determinants for the better performance of filtering for the BS campaign were related to smaller LOI content, the lower value of specific surface area and smaller proportions of porous mineral or greater roundness. In short, the mineralogy was the determining factor to justify differences between moisture cakes.
\end{abstract}

Keywords: Iron ore; Filtering; Pellet feed; Specific surface.

\section{INTRODUÇÃO}

No processo de pelotização, a característica do pellet feed (concentrado de minério de ferro com granulometria de $85 \%$ passante em $0,044 \mathrm{~mm}$ ) é determinante para o bom desempenho desta etapa, sendo o teor de umidade um dos parâmetros com impacto mais significativo na qualidade da pelota produzida. A etapa de filtragem é uma operação

\footnotetext{
'Pró-Reitoria de Pesquisa e Pós-graduação - PROPP, Universidade Federal de Ouro Preto - UFOP, Ouro Preto, MG, Brasil. E-mail: karinefernandes. bio@hotmail.com

${ }^{2}$ Departamento de Engenharia de Minas, Universidade Federal de Ouro Preto - UFOP, Ouro Preto, MG, Brasil.

${ }^{3}$ Programa de Pós-graduação em Engenharia Metalúrgica, Materiais e de Minas, Universidade Federal de Minas Gerais - UFMG, Belo Horizonte, MG, Brasil.
} 
de separação sólido-líquido fundamental para o processo produtivo da pelota, agindo no ajuste da umidade do pellet feed e, em paralelo, na recuperação da água de processo [I-4].

O filtro a disco é amplamente utilizado para filtragem de pellet feed de minério de ferro, seu custo inferior em relação aos outros modelos e a alta área de filtragem em relação à área de instalação é a primeira opção quando se projeta uma instalação de filtragem [4].

Muitos fatores podem influenciar o desempenho do filtro a disco afetando a produtividade $(\mathrm{t} / \mathrm{h})$ e a obtenção da torta com umidade desejada. Um dos fatores relacionados às condições operacionais do filtro, a escolha adequada do meio filtrante depende do compromisso entre a turbidez e concentração de sólidos no filtrado, produtividade do filtro, teor de umidade residual da torta e o seu custo [5]. Um bom meio filtrante deverá garantir a mínima propensão ao cegamento (obstrução dos poros pelas partículas solidas), capacidade de manter as partículas solidas sobre os poros, a partir do inicio da formação da torta, apresentando ainda resistência ao ataque químico, resistência mecânica, resistência ao desgaste, maleabilidade para se adaptar ao filtro e custo compatível com a economia da operação $[6,7]$. Muitas destas características são inconciliáveis.

Mesmo se fosse possível controlar todas as variáveis operacionais do processo de filtragem, as características intrínsecas do minério ainda trarão impactos significativos no processo de filtragem. Variáveis como composição mineralógica do pellet feed, a área superficial específica, PPC (perda por calcinação), porosidade e forma das partículas, são determinantes para o desempenho do filtro [8].

O teor elevado de PPC no minério leva ao desbalanceamento na relação da granulometria com a superfície específica, podendo implicar em granulometria mais grossa para atendimento da meta de superfície específica ou superfície específica elevada para atendimento à meta de granulometria $[9,10]$.

A superfície específica expressa a área superficial por grama de um determinado produto. A sua magnitude influencia diretamente na eficiência da filtragem, maiores valores provocam menor permeabilidade dos tecidos filtrantes (Figura I), e consequentemente maior umidade

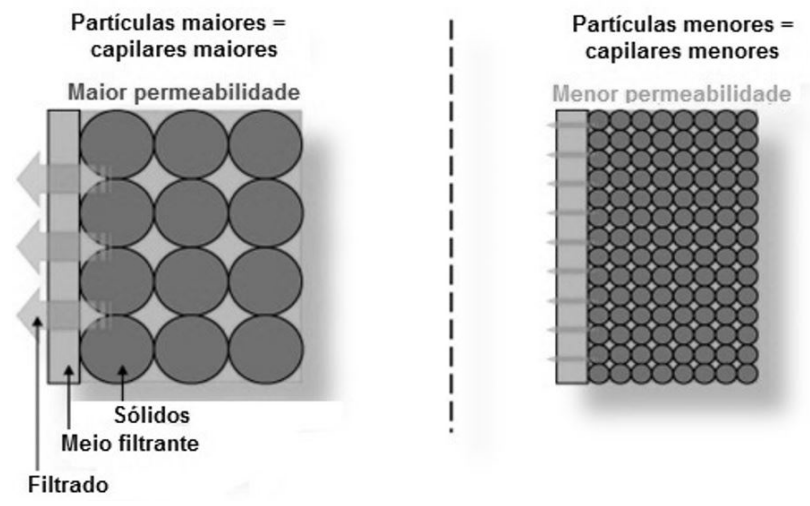

Figura I. Permeabilidade do tecido com alta e baixa superfície específica, Andrade [10]. da torta, prejudicando a produtividade, elevando de forma significativa os custos de produção [4]. Além disso, a superfície específica é uma variável essencial para o processo de pelotização, quanto maior a superfície específica média, maior a energia superficial das partículas, o que favorece - processo de pelotização. Por outro lado, a superfície específica demasiadamente elevada impacta negativamente no desempenho da filtragem, causando o aumento da umidade da torta e/ou comprometendo a produtividade do filtro [I I ].

Andrade [10] estudou utilização de reagente redutor de umidade do pellet feed para etapa de filtragem na Samarco Mineração S.A. No estudo os autores demonstraram a relação entre PPC, superfície específica e produtividade da filtragem. Como mostrado nos gráficos das Figuras 2 e 3 , a superfície específica aumenta de acordo com o aumento do teor de PPC, e a produtividade está fortemente relacionada com a umidade da torta que aumenta de acordo com a superfície específica do minério.

A porosidade é outra característica que afeta fortemente a etapa de filtragem. Wakeman [6] avaliou a porosidade das partículas e notou que a elevação da porosidade gera uma redução da resistência específica e maior umidade na torta. De acordo com o trabalho realizado por Turrer [I I], em que estudaram $o$ efeito da mineralogia na filtragem do minério de ferro, observou-se que goethitas exibiam uma área de poros por partícula bem maior que os das hematitas, conforme ilustrado na Figura 4. Nas goethitas a média da área de poros por partícula foi de cerca de $100 \mathrm{~m}^{2}$ com um alto desvio padrão, cerca de $400 \mathrm{~m}^{2}$. Já na hematita a média foi igual a $30 \mathrm{~m}^{2}$ com desvios de $54 \mathrm{~m}^{2}$ e $189 \mathrm{~m}^{2}$, respectivamente, para faixa fina e grossa. Além disso, a quantidade de partículas com poros em relação ao número de partículas total é muito maior nas goethitas, $35 \%$, do que nas hematitas, $16 \%$.

O formato das partículas, é reconhecido como uma das propriedades fundamentais, que pode afetar, por exemplo, o empacotamento, a densidade, a porosidade, a permeabilidade, a coesão entre outras propriedades [12-15]. Partículas diferentes podem ser consideradas, equivocadamente, como idênticas se apenas a distribuição granulométrica for levada em conta.

De acordo com Connell [14] é esperado que a forma das partículas influencie na estrutura da torta de filtração formada. Boskovic [15] realizaram experimentos utilizando nano partículas, esféricas e cúbicas, com o objetivo de verificar a influência da forma na eficiência da filtração. Os resultados mostraram que a eficiência de filtração foi menor para as partículas cúbicas. Os autores concluíram que a razão para a diferença estava no movimento das partículas ao longo da superfície das fibras do tecido. As partículas esféricas depois de tocar a fibra podem deslizar ou rolar e as partículas cubicas apenas deslizam ou "tombam", nesta fase, as partículas podem tocar a fibra com as laterais ou com as arestas, o que muda a superfícies de contato entre a fibra e a partícula significativamente, e aumenta a possibilidade da partícula não ficar retida na fibra [16]. 
PPCC

$\%$

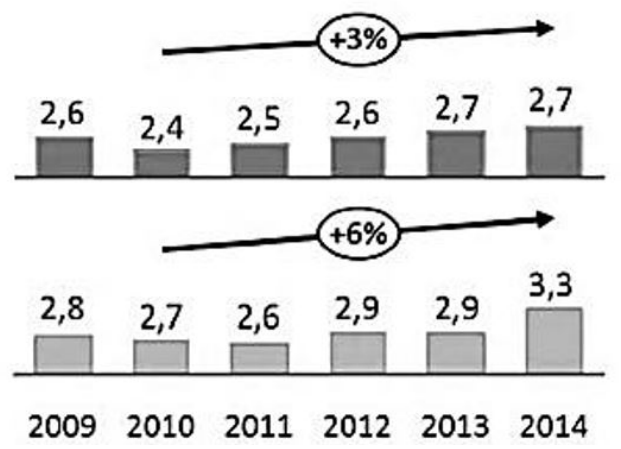

\section{Superfície específica}

$\mathrm{cm} 2 / \mathrm{g}$
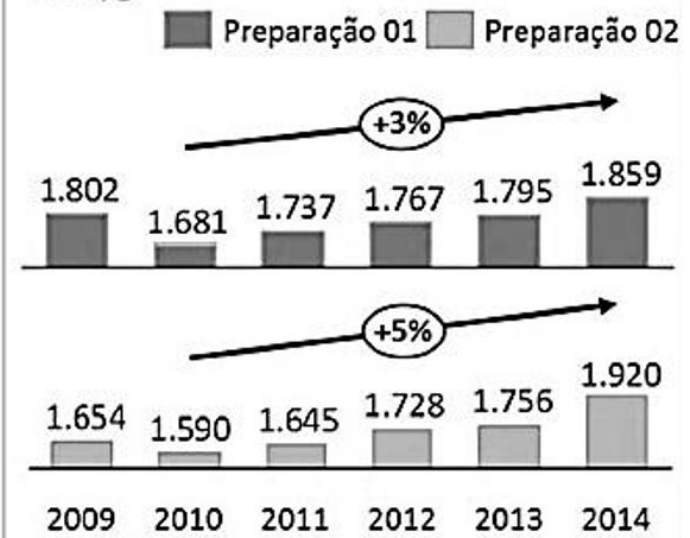

Figura 2. Histórico de PPC e superfície específica, Andrade [10].

Produtividade $x$ Umidade $x$ Superfície Específica

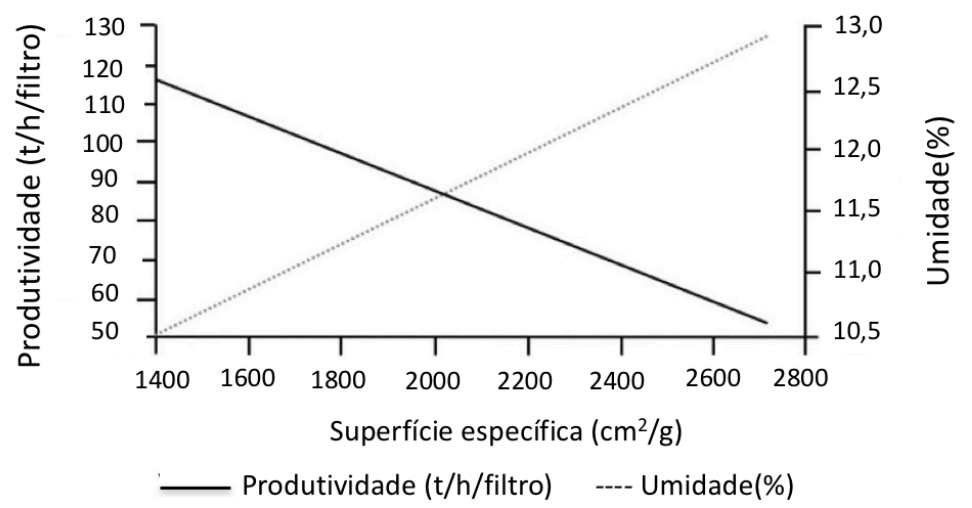

Figura 3. Histórico de umidade nas preparações, modificado de Andrade [10].
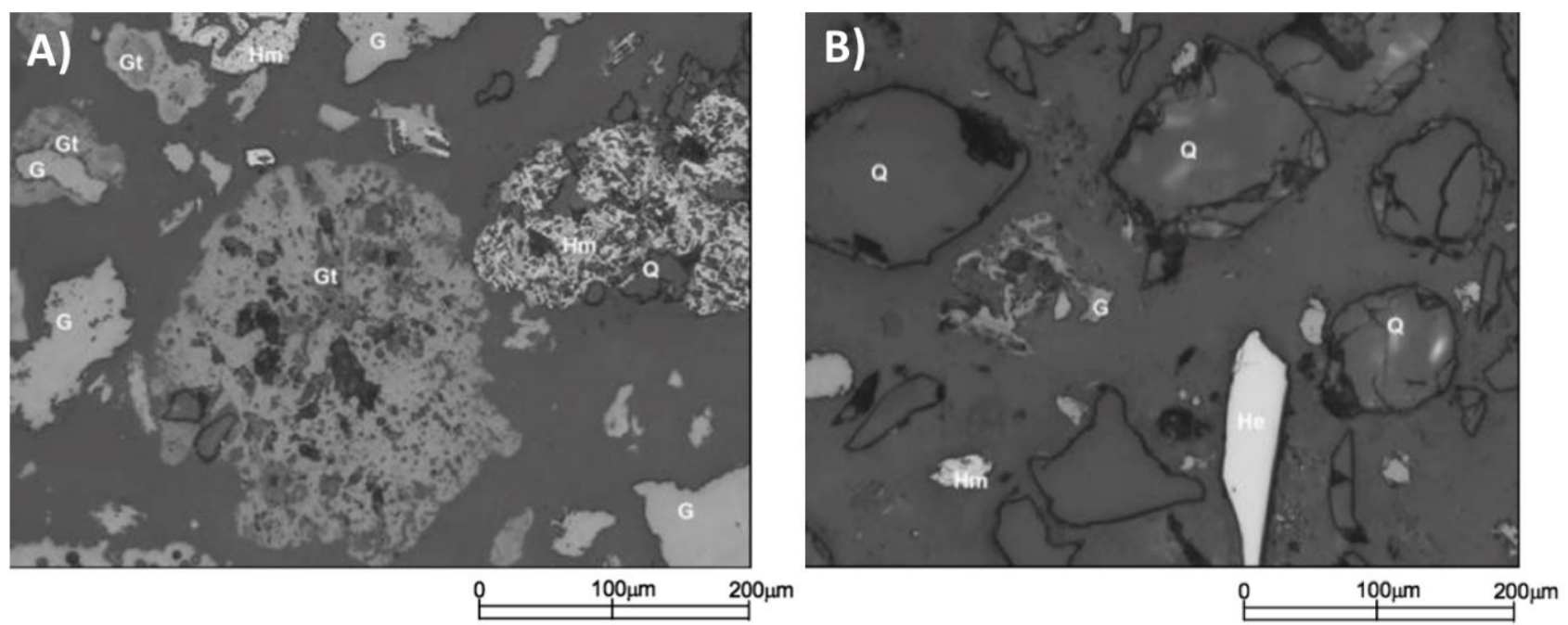

Figura 4. (A) Partícula de goethita (Gt) na porção central da fotomicrografia (aumento de 200X) exibindo a presença de muitos poros; (B) Hematita lamelar na porção inferior da fotomicrografia (aumento de 200X) com praticamente nenhuma porosidade, Rocha [7]. 
Segundo Wakeman [6], para uma filtragem eficiente, a forma da partícula deve ser mais próxima do formato esférico. Turrer [ $\mathrm{I} \mathrm{I}]$ concluíram que as partículas de hematita especular apresentam esfericidade média maior que a goethita, e que $\circ$ fator forma das partículas de goethita impactaram de forma negativa no desempenho da filtragem.

Nos últimos anos, as empresas expandiram suas operações buscando aumento da produção mineral para atender as crescentes demandas por minérios de ferro. Para incrementar as reservas de minério, houve a incorporação de minérios mais complexos, por exemplo, com teores mais elevados de PPC (perda por calcinação) que anteriormente eram considerados como estéreis. Estes tipos de minérios mais hidratados são compostos essencialmente por goethita, que é um hidróxido de ferro, produto do processo de enriquecimento supergênico, atuante na gênese do minério de ferro $[7,17]$.

Desta forma, este trabalho objetiva avaliar e compreender os impactos relativos aos seguintes parâmetros no processo de filtragem: superfície específica, características químicas, granulométricas e mineralógicas do concentrado.

\section{MATERIAIS E MÉTODOS}

Para entender a influência das características intrínsecas do minério na etapa de filtragem, foram realizadas comparações entre informações obtidas pela caracterização das amostras de concentrado de minério de ferro (alimentação do filtro) e informações a respeito da umidade final da torta após filtragem e produtividade da linha de filtragem.

As amostras de concentrado (alimentação do filtro) foram coletadas em duas diferentes campanhas de produção industrial durante duas semanas. As duas campanhas de produção se distinguem pela qualidade final do concentrado produzido, principalmente teor de $\mathrm{SiO}_{2}$. Uma das campanhas corresponde a concentrados de baixo teor de $\mathrm{SiO}_{2}(<\mathrm{I}, 2 \%)$, denominada aqui neste trabalho de campanha BS, a outra campanha corresponde a concentrados de teores mais elevados de $\mathrm{SiO}_{2}(<\mathrm{I}, 5 \%)$, denominada como campanha AS.
Entre os dias I2/09/2015 e 27/09/2015 foram coletadas diariamente cerca de $2,1 \mathrm{~kg}$ de concentrado produzido. As amostras que representam o composto diário foram caracterizadas para obtenção das informações relevantes na interpretação dos resultados da etapa de filtragem.

Cada uma das amostras $(2,1 \mathrm{~kg})$ foi homogeneizada e quarteada para retirada de alíquotas que foram encaminhadas às etapas da caracterização. A partir de análise química foram obtidos teores de $\mathrm{Fe}$ e $\mathrm{FeO}$ por dicromatometria (métodos por cloreto de titânio), teor de PPC (perda por calcinação ou perda ao fogo) por gravimetria e teores de $\mathrm{Al}_{2} \mathrm{O}_{3}, \mathrm{P}$ e $\mathrm{Mn}$ por ICP-OES.

A área superficial específica foi determinada pelo método Blaine. As análises mineralógicas das amostras foram realizadas por microscopia ótica de luz refletida com a contagem dos grãos de óxidos e hidróxido de ferro, considerando as porcentagens de hematita especular (HE), hematita martítica $(H M)$ goethita $(G)$ e magnetita (MA) e dos minerais de ganga.

Os resultados da caracterização das amostras que representam o composto diário foram ponderados pela produção total de concentrado para composição de um resultado médio global para campanha BS e para campanha AS. O mesmo foi feito com os dados de umidade e produtividade, sendo esses ponderados pela produção total de filtragem. As amostras dos dias 12, 13, 14, 15, 16, 17, 18 e 19/09/2015 correspondem à campanha $\mathrm{AS}$ e as amostras dos dias 20,21, $22,23,24,26$ e 27/09/20I 5 correspondem à campanha BS.

\section{RESULTADOS E DISCUSSÃO}

$\mathrm{Na}$ Tabela I estão apresentados os resultados e as médias da umidade da torta e da produtividade após o processo de filtragem dos minérios ao longo das campanhas de produção BS e AS.

Observou-se que na campanha AS os valores médios de produtividade foram superiores àqueles obtidos na campanha BS, apresentando médias de $67,6 \mathrm{tms} / \mathrm{h} /$ filtro e $63,29 \mathrm{tms} / \mathrm{h} /$ filtro respectivamente. Acredita-se que essa diferença na produtividade foi um dos fatores que

Tabela I. Dados referentes ao desempenho do minério na etapa de filtragem

\begin{tabular}{|c|c|c|c|c|c|}
\hline \multicolumn{3}{|c|}{ Campanha AS } & \multicolumn{3}{|c|}{ Campanha BS } \\
\hline Dia & Umidade (\%) & $\begin{array}{c}\text { Produtividade } \\
\text { (tms/h/filtro) }\end{array}$ & Dia & Umidade (\%) & $\begin{array}{c}\text { Produtividade } \\
\text { (tms/h/filtro) }\end{array}$ \\
\hline 12 & 10,66 & 66,66 & 20 & 10,40 & 64,97 \\
\hline 13 & 10,59 & 66,16 & 21 & 10,32 & 64,63 \\
\hline 14 & 10,49 & 67,36 & 22 & 10,26 & 64,45 \\
\hline 15 & 10,33 & 70,43 & 23 & 10,14 & 63,28 \\
\hline 16 & 10,26 & 68,81 & 24 & 10,13 & 63,07 \\
\hline 17 & 10,15 & 66,91 & 25 & 10,18 & 62,32 \\
\hline 18 & 10,25 & 64,13 & 26 & 10,20 & 62,32 \\
\hline 19 & 10,48 & 70,34 & 27 & 10,13 & 61,28 \\
\hline Média & 10,40 & 67,60 & Média & 10,22 & 63,29 \\
\hline
\end{tabular}


determinou uma menor umidade na campanha BS (10,2\%) quando comparado ao valor de umidade na AS (10,4\%), pois a maior produtividade resulta em um menor tempo de residência da torta no filtro resultando em um menor desaguamento da torta.

Os valores médios de umidade apresentam diferença absoluta muito pequena, de apenas $0,18 \%$, porém significativa para os processos subsequentes, principalmente para a pelotização. Diante disto foi aplicado o teste estatístico $t$ de student para duas populações de amostras, com intuito de verificar se existe diferença estatística significativa entre as médias de umidade das campanhas AS e BS em um grau de confiança de $95 \%$. Na Figura 5 é apresentado o resultado obtido a partir do teste realizado no software Minitab 18.
Conforme observado, o valor-P de 0,032 sendo inferior a 0,05 significa que a hipótese nula $\left(\mathrm{H}_{0}: \mu_{1}-\mu_{2}=0\right)$ deve ser rejeitada, ou seja, existe diferença estatística significativa entre os valores médios de umidade das campanhas AS e BS para um intervalo de confiança de $95 \%$.

Os teores de Fe e PPC e os valores de área superficial específica das campanhas BS e AS estão exibidos na Tabela 2. Os teores de ferro dos concentrados obtidos foram muito semelhantes nas duas campanhas, sendo que o teor médio da BS foi levemente superior $(66,9 \%)$ ao teor médio dos produtos da campanha AS $(66,2 \%)$.

Com relação aos teores de PPC, é possível observar que são nitidamente distintos entre os concentrados das duas campanhas, sendo o teor médio da campanha BS igual

\section{Teste T para Duas Amostras e IC: UMIDADE_AS, UMIDADE_BS}

\section{Método}

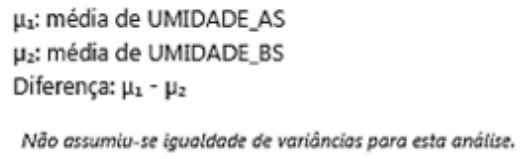

\begin{tabular}{lcccc} 
Amostra & $\mathrm{N}$ & Média & DesvPad & EP Média \\
\hline UMIDADE_AS & 8 & 10,401 & 0,180 & 0,064 \\
UMIDADE_BS & 8 & 10,220 & 0,099 & 0,035
\end{tabular}

Estimativa da diferença

\begin{tabular}{cc} 
IC de $95 \%$ para \\
Diferença & a Diferença \\
\hline $0,1813 \quad(0,0192 ; 0,3433)$
\end{tabular}

Teste

\begin{tabular}{|c|c|c|c|}
\hline \multicolumn{3}{|c|}{$\begin{array}{l}\text { Hipótese nula } \\
\text { Hipótese alternativa }\end{array}$} & $\begin{array}{l}H_{0}: \mu_{1}-\mu_{2}=0 \\
H_{2}: \mu_{2}-\mu_{2} \neq 0\end{array}$ \\
\hline Valor-T & GL & Valor-p & \\
\hline 2,49 & 10 & 0,032 & \\
\hline
\end{tabular}

Figura 5. Resultado do teste $t$ de student para os valores médios de umidade das campanhas AS e BS.

Tabela 2. Resultados da análise química e da área superficial específica do minério da alimentação da filtragem nas campanhas BS e AS

\begin{tabular}{|c|c|c|c|c|c|c|c|}
\hline \multicolumn{4}{|c|}{ Campanha AS } & \multicolumn{4}{|c|}{ Campanha BS } \\
\hline Dia & $\mathrm{Fe}(\%)$ & PPC (\%) & $\begin{array}{c}\text { Área Superficial } \\
\text { Específica } \\
\left(\mathrm{g} / \mathrm{cm}^{3}\right)\end{array}$ & Dia & $\mathrm{Fe}(\%)$ & PPC (\%) & $\begin{array}{c}\text { Área Superficial } \\
\text { Específica } \\
\left(\mathrm{g} / \mathrm{cm}^{3}\right) \\
\end{array}$ \\
\hline 12 & 65,94 & 3,08 & 1773 & 20 & 66,99 & 2,23 & 1677 \\
\hline 13 & 66,44 & 2,86 & 1717 & 21 & 66,91 & 2,32 & 1673 \\
\hline 14 & 66,22 & 3,07 & 1773 & 22 & 66,94 & 2,34 & 1669 \\
\hline 15 & 66,17 & 3,18 & 1691 & 23 & 66,90 & 2,34 & 1597 \\
\hline 16 & 66,08 & 2,99 & $|86|$ & 24 & 66,89 & 2,49 & 1548 \\
\hline 17 & 66,05 & 3,53 & 1943 & 25 & 66,93 & 2,38 & 1638 \\
\hline 18 & 66,41 & 3,08 & 1670 & 26 & 67,06 & 2,28 & 1603 \\
\hline 19 & 66,58 & 2,64 & 1683 & 27 & 66,76 & 2,69 & 1622 \\
\hline Média & 66,24 & 3,05 & 1763 & Média & 66,92 & 2,38 & 1628 \\
\hline
\end{tabular}


Tabela 3. Composição mineralógica do concentrado das campanhas BS e AS

\begin{tabular}{ccccc}
\hline \multicolumn{5}{c}{ Composição Mineralógica (\%) } \\
\hline Campanha & HE & HM & G & MA \\
\hline BS & 54,9 & 27,0 & 15,0 & 3,1 \\
AS & 43,9 & 30,3 & 21,2 & 4,6 \\
\hline
\end{tabular}

Sendo: HE - Hematita Especular; HM - Hematita em Martita; G - Goethita e MA - Magnetita.

a 2,38\% enquanto que o teor médio de PPC da campanha AS foi igual a $3,05 \%$. O teor de PPC é uma das variáveis que também influencia na obtenção da umidade da torta, pois quanto maior o teor de PPC, maior tende a ser a umidade.

$O$ teor de PPC indica maior presença de goethita entre os minerais constituintes do minério. A goethita influencia na geração de área superficial específica, o que contribui para maiores valores de umidade na torta. Os valores da área superficial específica dos concentrados da campanha AS foram sistematicamente mais elevadas do que da campanha BS, com valores médios de $1763 \mathrm{~g} / \mathrm{cm}^{3}$ e $1628 \mathrm{~g} / \mathrm{cm}^{3}$, respectivamente.

A composição mineralógica é o fator que pode ter determinado essa diferença na área superficial específica, a maior presença de hematita especular na campanha BS convergiu para maior dificuldade na geração de área superficial específica. Os resultados da composição mineralógica do minério da campanha BS e AS estão apresentados na Tabela 3. O minério que compõe a campanha BS é constituído basicamente por $54,9 \%$ de hematita especular, $27 \%$ de hematita martítica, $15 \%$ de goethita e 3,1\% de magnetita. Já o minério da campanha AS apresentou teor de hematita especular de $43,9 \%$, teor de hematita martítica de $30,2 \%$, de goethita de $21,2 \%$ e de magnetita de $4,6 \%$.

Como a porcentagem de hematita especular foi maior na campanha $\mathrm{BS}$, foi necessário moer o minério a uma granulometria mais fina para obtenção da área superficial específica necessária ao processo, enquanto que para a campanha AS provavelmente pela presença da goethita em um teor mais elevado, foi possível obter maiores valores de área superficial específica com menor grau de cominuição.

Apesar da porcentagem de passante em $45 \mu \mathrm{m}$ não seguir a tendência da elevação da área superficial específica, os resultados foram coerentes, uma vez que na campanha AS houve maior área superficial específica e maior umidade e na campanha BS uma menor umidade e menor área superficial específica, fato este explicado pelas características mineralógicas das amostras.

A porosidade também é um fator que pode influenciar o desempenho da filtragem. A água pode ficar "aprisionada" nos poros das partículas devido a propriedade de capilaridade associada à tensão superficial da água. Dentre os minerais que constituem os minérios das campanhas BS e AS, a hematita martítica e a goethita são aqueles que apresentam maior porosidade, enquanto que a hematita especular e a magnetita são minerais compactos, considerados não porosos. Somando os teores da hematita martítica e da goethita, nota-se que na campanha $A S$, esses minérios somam $5 \mathrm{I}, 5 \%$ enquanto que na campanha BS somam 42, $1 \%$. Sugere-se que os minérios da campanha $A S$ apresentam maior dificuldade para retirada de água em comparação ao minério da BS, devido ao maior volume de poros das partículas, o que é coerente com os resultados apresentados, com o maior valor de umidade na campanha AS.

A forma da partícula também é um dos fatores que impactaram na filtragem, as partículas de hematita especular apresentam esfericidade média maior que a goethita, portanto, a maior participação da goethita na campanha AS, pode ter influenciado de forma negativa o desempenho da filtragem, uma vez que sua baixa esfericidade pode ter contribuído para o cegamento parcial do tecido filtrante levando ao aumento da umidade.

\section{CONCLUSÕES}

$\mathrm{Na}$ campanha de produção de concentrado com menor teor de $\mathrm{SiO}_{2}$, o valor de umidade foi igual a $10,2 \%$, enquanto o valor da umidade do produto da campanha com maior teor de $\mathrm{SiO}_{2}$ foi de $10,4 \%$. Os principais fatores responsáveis pelo melhor desempenho da filtragem do minério da campanha com maior restrição de qualidade são relacionados ao menor teor de PPC, menor valor de área superficial específica e menores proporções de minerais porosos ou de maior esfericidade. Considerando as variáveis estudadas, a mineralogia foi o fator determinante para justificar as diferenças entre as umidades das tortas, no entanto, fatores relacionados à operação da filtragem, devem ser considerados na análise em estudos futuros para um melhor entendimento da real influência das características intrínsecas do minério na etapa de filtragem.

\section{Agradecimentos}

Os autores agradecem aos seguintes órgãos e instituições: Universidade Federal de Ouro Preto (UFOP), Pró-Reitoria de Pesquisa e Pós-Graduação (PROPP).

\section{REFERÊNCIAS}

I Amarante SC. Filtragem na indústria mineral. Metalurgia \& Materiais. 200 /;57(5I5):647-648.

2 Fonseca MC. Influência da distribuição granulométrica do pellet feed no processo de aglomeração e na qualidade da pelota de minério de ferro para redução direta [Dissertação de mestrado]. Ouro Preto: Universidade Federal de Ouro Preto; 2004. 
3 Pereira PM. Influência do antracito adicionado à mistura de pelotização sobre as características físicas das pelotas queimadas [Dissertação de mestrado]. Belo Horizonte: Universidade Federal de Minas Gerais; 2016.

4 Rushton A, Ward AS, Holdich RG. Solid-liquid filtration and separation technology. 2nd ed. Weinheim: Wiley-VCH; 2000.

5 Purchas DB, Sutherland K. Handbook of filter media. 2nd ed. Kidlington: Elsevier Science; 2002.

6 Wakeman R. The influence of particle properties on filtration. Separation and Purification Technology. 2007;58:234$24 \mathrm{I}$.

7 Rocha JMP. Definição da tipologia e caracterização mineralógica e microestrutural dos itabiritos anfibolíticos das Minas de Alegria da Samarco Mineração S.A. [Tese de doutorado]. Belo Horizonte: Universidade Federal de Minas Gerais; 2008.

8 Rodrigues OMS. Eparação sólido líquido. Ouro Preto: Universidade Federal de Ouro Preto; 2016. Apostila de aula: disciplina tratamento de minério.

9 Costa AMAR, Silva DS, Almeida KCF, Oliveira LM, Silva RVG, Auzier EC, et al. Modernização e padronização do ensaio de determinação de superfície específica nos laboratórios do sistema norte. In: Anais do $12^{\circ}$ Seminário de Redução de Minério de Ferro e Matérias-primas, Anais do $41^{\circ}$ Seminário Brasileiro de Minério de Ferro; 20II; Vila Velha, Brasil. Cidade: editora.

10 Andrade AG, Reis AS, Zuchi MA, Marchezi AS. Desenvolvimento de reagente redutor de umidade do pellet feed para etapa de filtragem na Samarco Mineração S.A. In: Anais do $45^{\circ}$ Seminário de Redução de Minério de Ferro e Materias-primas, Anais do $16^{\circ}$ Simpósio Brasileiro de Minerio de Ferro, Anais do $3^{\circ}$ Simpósio Brasileiro de Minerio de Ferro; 20I5; Rio de Janeiro. São Paulo: ABM; 2015.

I I Turrer HDG, Zuchi MA, Marchezi AS, Medeiros B, Simoes HO, Araujo AM Jr, et al. Efeito da mineralogia na filtragem de minério de ferro. In: Associação Brasileira de Metalurgia, Materiais e Mineração. Anais do $41^{\circ}$ Seminário de Redução de Minério de Ferro e Matérias-primas, Anais do $12^{\circ}$ Seminário Brasileiro de Minério de Ferro; 20II; Vila Velha. São Paulo: ABM; 20II.

12 Hawkins AE. Characterizing the single particle. In: Rhodes M. Principles of powder technology. USA: John Wiley \& Songs Ltd; 1990. p. 9-3I.

13 Azevedo SGR. Estudo da influência do formato das partículas na operação de filtração de gases [Dissertação de mestrado]. São Carlos: Universidade Federal de São Carlos; 2009.

14 Connell H, Zhu J, Bassi A. Effect of particle shape on crossflow filtration flux. Journal of Membrane Science. 1999;153:121-139.

I5 Boskovic L, Altman IS, Agranovski IE, Braddock RD, Myojo T, Choi M. Influence of particle shape on filtration processes. Aerosol Science and Technology. 2005;39(I2): I I84-I 190.

16 Silva AM. Caracterização do processo de degradação de uma fibra de poliamida utilizada como meio filtrante na indústria mineral [Dissertação de mestrado]. Universidade Federal de Ouro Preto; 2006.

17 Rodrigues RS. Grau de Liberação de diferentes tipos de itabiritos das minas de alegria (mariana-mg) e sua influência nas etapas de cominuição e concentração [Dissertação de mestrado]. Belo Horizonte: Escola de Engenharia, Universidade Federal de Minas Gerais; 2016.

Recebido em: 09 Mai. 2018

Aceito em: 23 Nov. 2018 